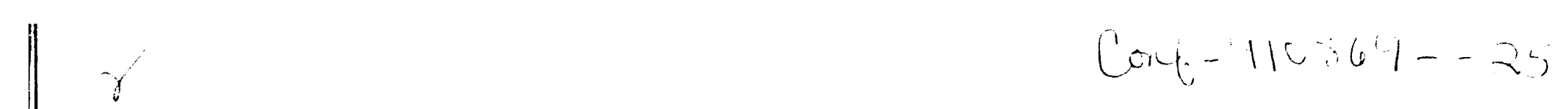

GA-A20693

\title{
NOV 131991 \\ FUNDAMENTAL AND SECOND HARMONIC HYDROGEN FAST-WAVE HEATING ON DIII-D
}

\author{
C.C. PETTY, R.I. PINSKER, M.J. MAYBERRY, M. PORKOLAB, \\ P.T. BONOLI, R. PRATER, F.W. BAITY, R.H. GOULDING, \\ and D.J. HOFFMAN
}

OCTOBER 1991

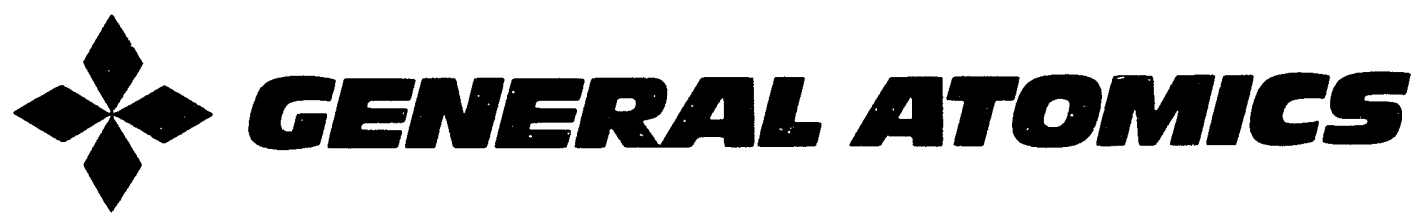




\section{DISCLAIMER}

This report was prepared as an account of vrork sponsored by an agency of the United States Government. Neither the United States Goverament nor any agency thereof, nor eny of their employees, makes any warranty, express or implied, or assumes any legal liability or responsibility for the accuracy, completeness, or usefulness of any information, apparatus, product, or process disclosed, or represents that its use would not infringe privately owned rights. Reference herein to any specific commercial product, process, or service by trade name, trademark, manufacturer, or otherwise, does not necessarily constitute or imply its endorsement, recommendation, or favoring by the United States Government or any agency thereof. The views and opinions of authors expressed herein do not necessarily state or reflect those of the United States Government or any agency thereof. 


\title{
FUNDAMENTAL AND SECOND HARMONIC HYDROGEN FAST-WAVE HEATING ON DIII-D
}

\author{
by \\ C.C. PETTY, R.I. PINSKER, M.J. MAYBERRY, M. PORKOLAB,* \\ P.T. BONOLI,* R. PRATER, F.W. BAITY, ${ }^{\dagger}$ R.H. GOULDING, ${ }^{\dagger}$ \\ and D.J. HOFFMAN ${ }^{\dagger}$
}

This is a preprint of a paper presented at the Ninth Topical Conference on the Radio Frequency, August 19-21, 1991, in Charleston, South Carolina, and to be printed in the Proceedings.

Work supported by U.S. Department of Energy

Contract Nos. DE-AC03-89ER51114 and DE-AC05-840R21400

* Plasma Fusion Center, MIT, USA.

† Oak Ridge National Laboratory, USA.

\section{GENERAL ATOMICS PROJECT 3466 OCTOBER 1991}

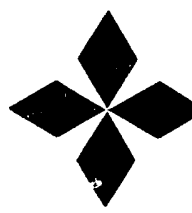

\section{GENERAL

ATOMICS 


\title{
FUNDAMENTAL AND SECOND HARMONIC HYDROGEN FAST-WAVE HEATING ON DIII-D*
}

\author{
C.C. Petty, R.I. Pinsker, M.J. Mayberry, \\ M. Porkolab,$^{\dagger}$ R. Prater
}

General Atomics, P.O. Box 85608, San Diego, California 92138-5608

F.W. Baity, R.H. Goulding, D.J. Hoffman

Oak Ridge National Laboratory, Oak Ridge, Tennessee 37831

\section{INTRODUCTION}

Ion cyclotron resonance heating (ICRH) with fast waves has been investigated on DIII-D in both the fundamental hydrogen minority $(32 \mathrm{MHz}, 2.14 \mathrm{~T}$ ) and second harmonic hydrogen majority $(60 \mathrm{MHz}, 1.97 \mathrm{~T})$ regimes. The main purpose of these experiments was to characterize the fast wave coupling and propagation in preparation for upcoming fast wave current drive (FWCD) experiments. For the fundamental minority regime, the electron and ion heating, global confinement, and radiated power fraction are compared for ICRH and NBI discharges with $P_{\text {aux }} \approx 1 \mathrm{MW}$.

The ICRH experiments were conducted using a four strap antenna which was designed for current drive experiments. ${ }^{1}$ The antenna is fed by a single $2 \mathrm{MW}$ 30-60 $\mathrm{MHz}$ transmitter. For ICRH experiments, either $(0,0,0,0)$ or $(0, \pi, 0, \pi)$ phasing was used. The launched parallel index of refraction for $(0, \pi, 0, \pi)$ phasing is $\left|n_{\|}\right| \approx 21$ at $32 \mathrm{MHz}$, and $\left|n_{\|}\right| \approx 11$ at $60 \mathrm{MHz}$.

\section{FUNDAMENTAL HEATING}

Ion cyclotron resonance heating experiments on DIII-D in the fundamental hydrogen minority regime displayed similar heating characteristics to neutral beam injection (NBI). A single-shot comparison of ICRH and NBI at equal injected power is shown in Fig. 1 for a single-null-divertor deuterium plasma with a $2 \%$ hydrogen fraction (measured spectroscopically). The diamagnetic stored energy increased by $40 \mathrm{~kJ}$ for both heating methods, though during NBI the stored energy determined from MHD analysis increased by $50 \mathrm{~kJ}$, indicating a significant parallel fast ion content. The central $T_{e}$ increased by $0.43 \mathrm{keV}$ during ICRH compared to $0.33 \mathrm{keV}$ during NBI, but the total radiated power was $125 \mathrm{~kW}$ greater during ICRH than during NBI.

The electron and ion temperature profiles during ICRH and NBI are compared in Fig. 2. The temperature profiles during ICRH are slightly more peaked than during NBI, indicating that the power deposition is more central. A full wave code analysis ${ }^{2}$ calculates that $72 \%$ of the of power is absorbed by the hydrogen minority at its fundamental resonance, while $28 \%$ of the if power is directly absorbed by the electrons through electron Landau damping and transit time

- Work supported by the U.S. Department of Energy under Contract Nos. DE-AC0389ER51114 and DE-AC05-84OR21400.

$\dagger$ Plasma Fusion Center, MIT, Cambridge, Massachusetts 02139 
magnetic pumping. This direct electron absorption is a result of the high $\left|n_{\|}\right|$ launched by the four strap antenna at $32 \mathrm{MHz}$.

The energy confinement time during fundamental hydrogen minority heating from the ICRH database is plotted in Fig. 3 against the ITER-89 power law scaling relation: ${ }^{3}$

$$
\tau_{E}=0.048 I^{0.85} R^{1.2} a^{0.3} n^{0.1} B^{0.2}(A \kappa / P)^{0.5}
$$

The ITER scaling relations have previously been found to agree with $\mathrm{ECH}^{4}$ as well as NBI L-mode shots on DIII-D. Although the $32 \mathrm{MHz}$ ICRH database is not large, the energy confinement time during ICRH is in reasonable agreement with the ITER scaling relation.

The radiated power fraction, defined as the total radiated power emitted from inside the separatrix divided by the total input power, is plotted in Fig. 4 for the ohmic, ICRH, and NBI phases. At the highest if power levels, the radiated power fraction was slightly higher than during the ohmic or NBI phase. The measured $Z_{\text {eff }}$ during ICRH is shown in Fig. 5, and is also slightly higher than during the ohmic or NBI phase. As shown in Ref. 5, covering the vessel walls with a boron/carbon coating greatly decreased both the metal impurities and the radiated power.

The effectiveness of fundamental ICRH for high minority concentrations was studied by puffing in hydrogen gas on several shots. As the hydrogen fraction was raised from less than $3 \%$ to $\approx 25 \%$, the stored energy during ICRH decreased while the radiated power increased. However, even for hydrogen fractions as large as $25 \%$, significant electron heating was still observed, as shown in Fig. 6. Using Stix's isotropic formula for minority heating, ${ }^{6}$ for $\mathrm{H} /(\mathrm{H}+\mathrm{D})=0.25$ only $37 \%$ of the power absorbed by the hydrogen minority should go to the electrons via collisions with the minority tail. Since the electron heating from mode converted ion Bernstein waves is calculaied to be negligible, substantial direct electron heating may be occurring. ${ }^{\text {? }}$

\section{SECOND HARMONIC HEATING}

The time history of a typical ICRH shot in the second harmonic hydrogen majority regime is shown in Fig. 7. An ion temperature increase of $0.35 \mathrm{keV}$ during ICRH was observed by a neutral-particle charge-exchange (CX) analyzer. This mass-resolving CX analyzer, oriented perpendicular to the toroidal field, observed a significant hydrogen tail at 4-5 times the bulk ion temperature, as shown in Fig. 8. Since the hydrogen tail temperature is relatively low, the electron heating was relatively weak $\left(\Delta T_{e} \approx 0.15 \mathrm{keV}\right)$. The increase in stored energy indicated a plasma heating efficiency that was only $75 \%$ that for NBI heating or fundamental hydrogen minority heating. 


\section{CONCLUSIONS}

Plasma heating by fast waves was observed in both the fundamental hydrogen minority and second harmonic hydrogen majority regimes. In the fundamental minority regime, the global plasma heating was nearly the same as for NBI at equivalent power. The temperature profiles were slightly more peaked during ICRH than during NBI. Impurity influx and radiated power loss were slightly larger for the ICRH cases (without carbonization or boronization). Strong electron heating during ICRH was observed in this regime even with hydrogen fractions as large as $25 \%$. In the second harmonic majority regime, less efficient plasma heating was observed, though a perpendicular hydrogen tail at 4-5 times the bulk ion temperature was observed. These results demonstrate that the DIII-D FWCD antenna efficiently excites the fast wave.

\section{ACKNOWLEDGEMENT}

We thank Dr. Paul Bonoli for valuable discussions regarding the interpretation of these results.

\section{REFERENCES}

1

R.H. Goulding, these proceedings.

P.T. Bonoli and M. Porkolab, these proceedings.

3 ITER Team, "ITER Conceptual Design - Interim Report," IAEA, Vienna (1989).

4 T.C. Luce, etal., Plasma Physics and Controlled Nuclear Fusion 1990: in the Proceedings of the Thirteenth Conference on Plasma Physics and Controlled Nuclear Fusion, Washington, DC, October 1-6, 1990, (IAEA, Vienna, 1991), Vol. 2.

5 M.J. Mayberry, et al., these proceedings.

6 T.H. Stix, Nucl. Fusion 15, 737 (1975).

7 C.C. Petty, et al., "Direct electron heating by $60 \mathrm{MHz}$ fast waves DIII-D," these proceedings.

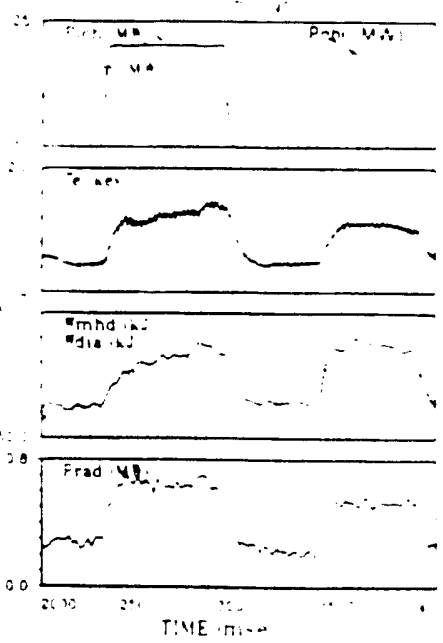

Fig. 1. Time history of fundamental hydrogen minority heating (first puise) and neutral beam injection (second pulse) $\left(\mathrm{I}_{\mathrm{p}}=0.7 \mathrm{MA}, \mathrm{B}_{\mathrm{T}}=2.14 \mathrm{~T}\right.$. $\left.\bar{n}=2 \times 10^{13} \mathrm{~cm}^{-3}\right)$.

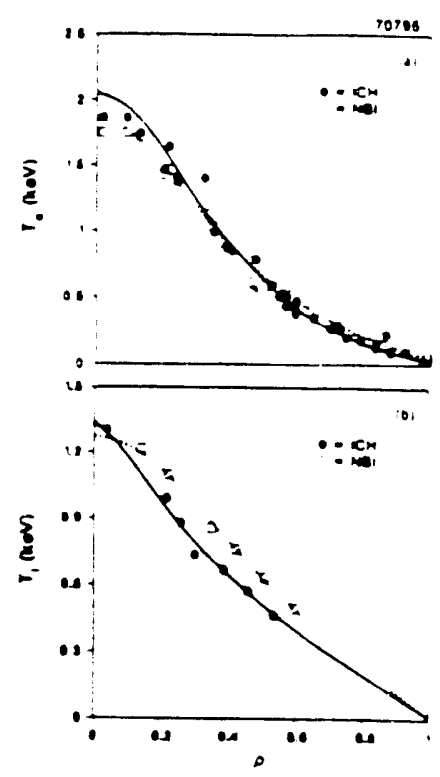

Fig. 2. Comparison of (a) electron temperature profile and (b) ion temperature profile during ICRH and NBI for the plasma shot shown in Fig. 1. 


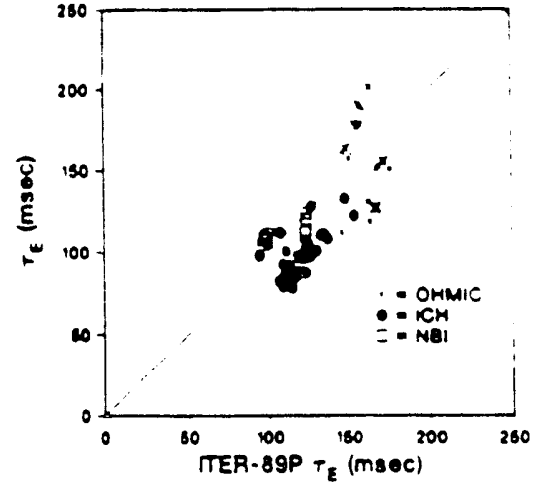

Fig. 3. Comparison of the energy confinement time during the ohmic, ICRH, and NBI phase with the ITER-89 power law scaling relation.

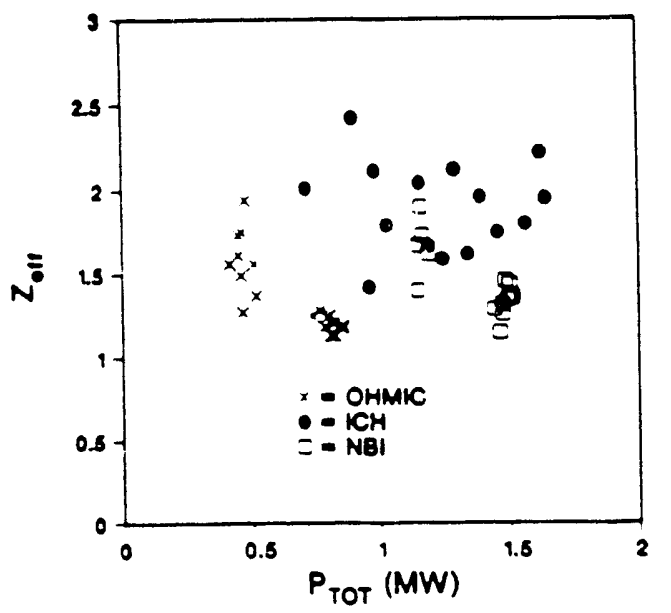

Fig. 5. $Z_{\text {eff }}$ during the ohmic, ICRH, and NBI phase.

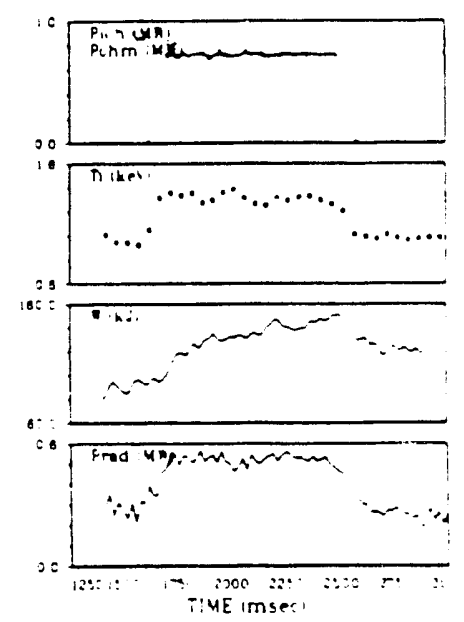

Fig. 7. Time history of second harmonic hydrogen heating for a hydrogen fraction of $53 \%\left(I_{p}=1 \mathrm{MA}\right.$, $\left.\mathrm{B}_{\mathrm{T}}=2.07 \mathrm{~T}, \bar{n}=2 \times 10^{13} \mathrm{~cm}^{-3}\right)$.

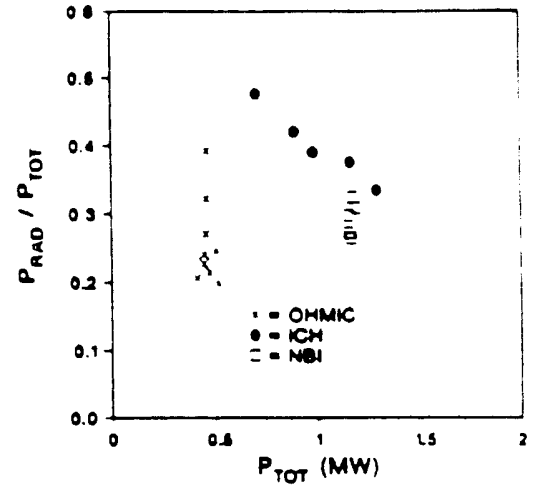

Fig. 4. Radiated power fraction during the ohmic, $I C R H$, and NBI phase $\left(I_{p}=0.7 \mathrm{MA}, B_{T}=2.14 \mathrm{~T}\right.$, $\bar{n}=2 \times 10^{13} \mathrm{~cm}^{-3}$ ).

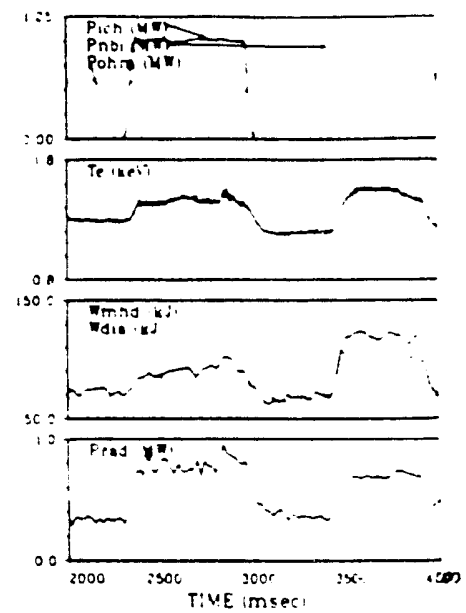

Fig. 6. Time history of fundamental hydrogen heating (first pulse) and neutral beam injection (ser.ond puise) for $25 \%$ hydrogen fraction $\left(I_{p}=0.7 \mathrm{MA}\right.$, $\mathrm{B}_{\mathrm{T}}=2.14 \mathrm{~T}, \bar{n}=2 \times 10^{13} \mathrm{~cm}^{-3}$ ).

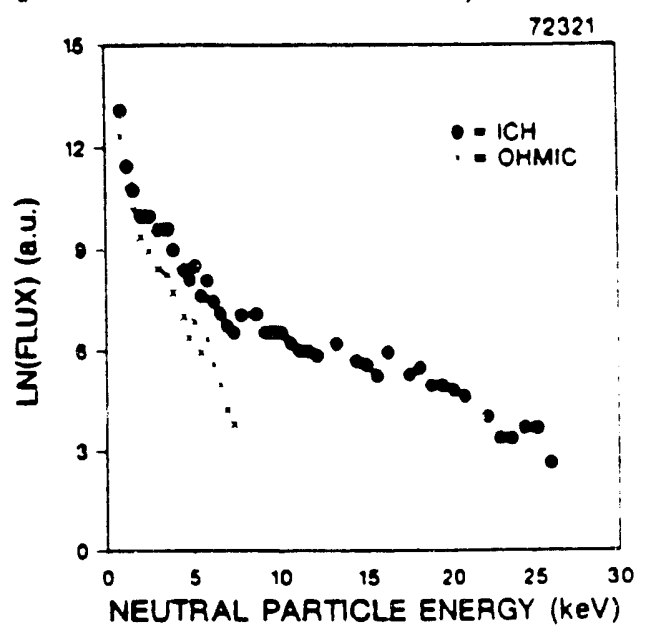

Fig. 8. Hydrogen tail observed by a neutral particle $C X$ analyzer during second harmonic hydrogen heating for a hydrogen fraction of $73 \%\left(I_{p}=1 \mathrm{MA}\right.$, $\mathrm{B}_{\mathrm{T}}=2.07 \mathrm{~T}, \bar{n}=2 \times 10^{13} \mathrm{~cm}^{-3}$ ). 
